\section{Microscopy Today New Publication Directions}

Ron Anderson and Charles Lyman*

Microscopy Today, Largo, FL and ${ }^{*}$ Lehigh University Bethlehem, PA microscopytoday@tampabay.rr.com

charles.lyman@Lehigh.EDU

Everything evolves. The Microscopy Society of America (MSA) purchased Microscopy Today (MT) from its founding editor, Don Grimes, and named Ron Anderson editor in 2002. Ron and Dale Anderson (MT Art Director) reformatted the magazine in 2002 and the magazine has enjoyed continuing success since that time. The format philosophy for Microscopy Today is to present 10 to 12 editorial articles plus NetNotes and Microscopy 101 as scientific content. Our aim has been to cover the entire field of microscopy giving even weight to all modalities. We have made progress in our efforts to be more universal with regard to different microscopies. We have made a point of providing editorial content in a dense format, with no white space, essentially, cramming in as much content for our readers as possible. We have kept MT as informal as possible-not mandating strict adherence to style rules-for example, we allow authors to format references any way they like as long as the reader can find the citation in question. And a little humor now and then can be found in our pages.

The magazine is free to microscopists in North America and to MSA members anywhere. A small subscription fee is charged for readers not qualified as above, but that barely covers postage. We give non-qualified authors of MT articles free one-year subscriptions. Advertising pays for the publication and distribution of MT. Magazines like MT are probably the primary reader source of information regarding vendors of instruments, services, and supplies in microscopy. In each issue our goal is to have not less than $50 \%$ editorial content relative to advertising content. We have never exceeded $40 \%$ advertising. The number of pages in any issue is determined by how many ad pages we have: more ads = more articles in any given issue. The ads are dispersed throughout the magazine on right-hand pages only, opposite editorial content, to be sure to give every ad the benefit of reader interest on every two-page spread.

Ron Anderson is trying to retire, and MSA Council has appointed Charles Lyman as his successor effective in 2009. Ron will stay on to help Charles in the transition. We are taking this opportunity to rethink MT's format and mode of doing business in this era of electronic publishing. The best way to begin a magazine reformatting process is to undertake a survey of the readers. Accordingly, we designed a survey and engaged Barbara Foster of Microscopy/ Microscopy Education to implement and conduct the survey for us. The survey was e-mailed to about 10,000 MT subscribers and we hoped for at least 450 responses back to us so as to guarantee a better than $\pm 3 \%$ confidence in the results. We were pleased to receive nearly 800 responses. Thank you to those that participated.

The survey results follow. Many questions had an "Other" choice. There were quite a few responses in this category-far too many to include here. Any reader wishing to view the "Other" responses is invited to contact one of the authors. The download will also contain cross-correlation data, e.g. How many earth scientists work in government, etc?

\section{Survey Results}

To better analyze the data, we began with a few demographic questions:

1. Which of the following best describes your DISCIPLINE?

- Biological Sciences (biology, biotech, medicine, pharmaceuticals)

- Physical Sciences (chemistry, physics, polymers or other materials science, Nanotechnology, semiconductors)

- Earth Sciences (geology, earth and environmental sciences)

- Forensics

- Food Sciences

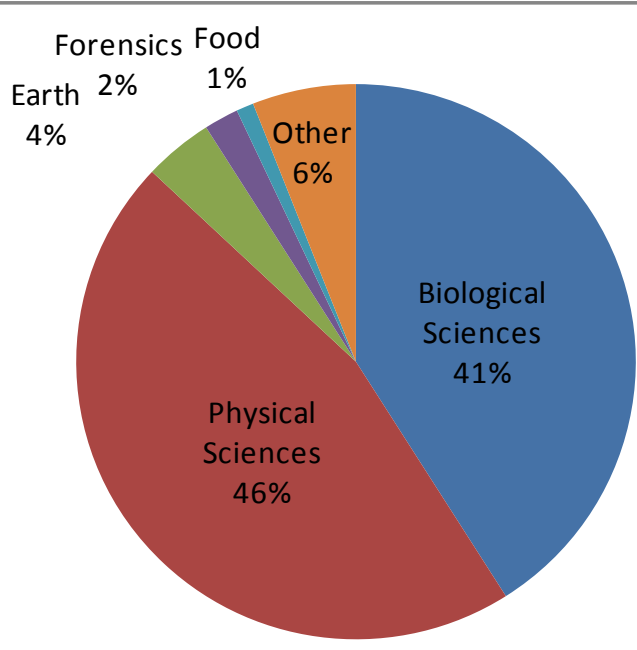

2. In which type of FACILITY or INSTITUTION do you work?

- Academic

- Industrial

- Governmental

- Clinical/Medical

- Vendor Supplier

- Consulting

- Home lab (Hobbyist, Amateur, Retired)

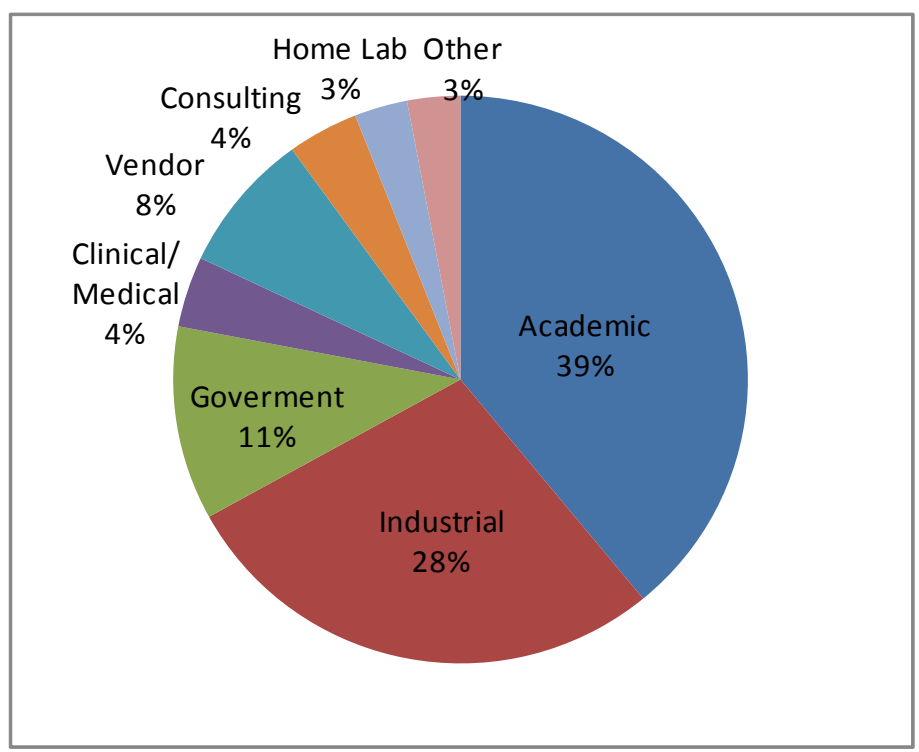




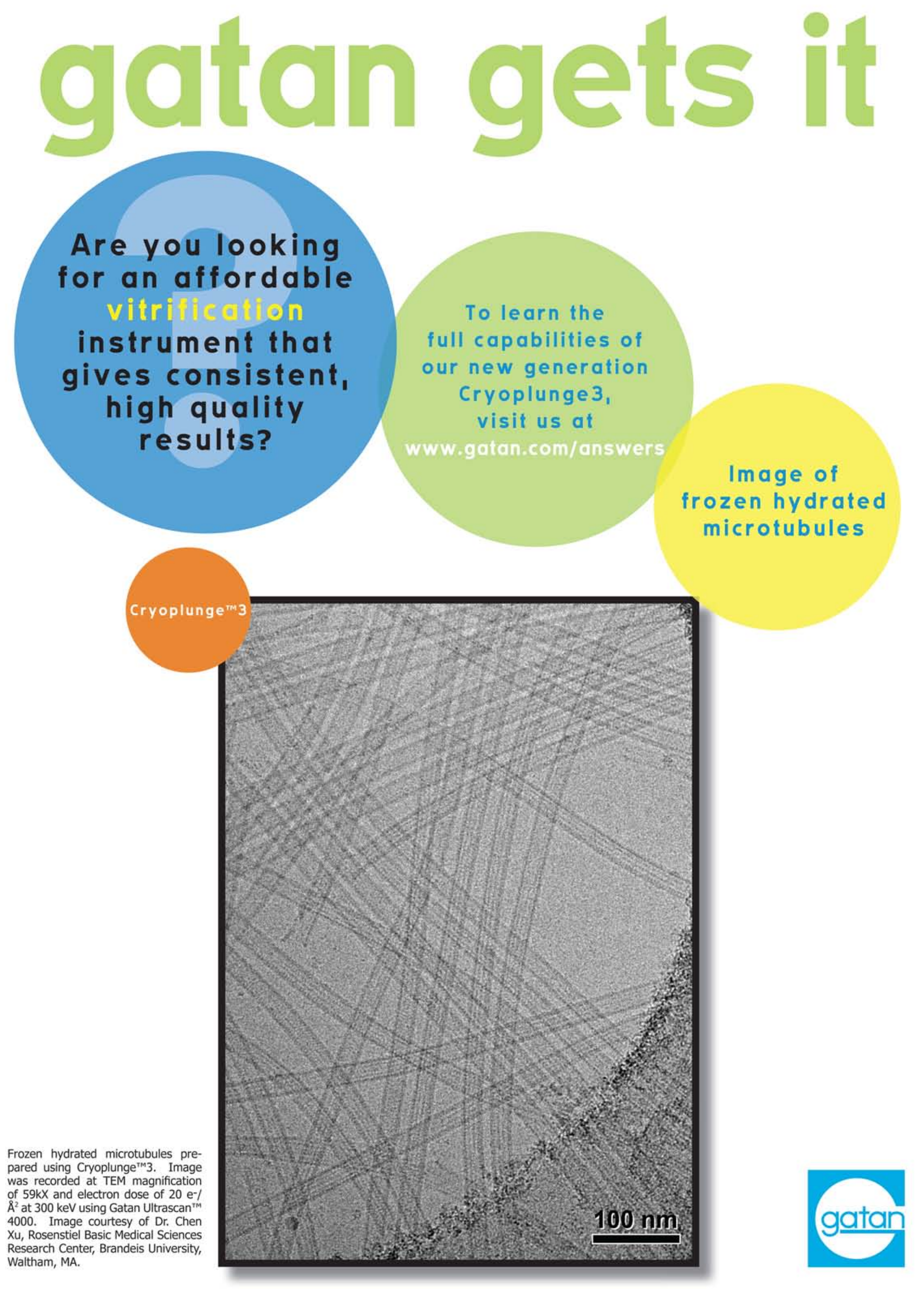


3. Which category best describes your POSITION or TITLE?

- Professor/Teacher

- Student (post-doc, grad student, undergraduate)

- Corporate Manager

- Lab Manager or Supervisor

- Researcher/Analyst

- Technologist/Technician/Maintenance/Support

- Engineer

- Consultant

- Amateur/Hobbyist

- Retired

- Other

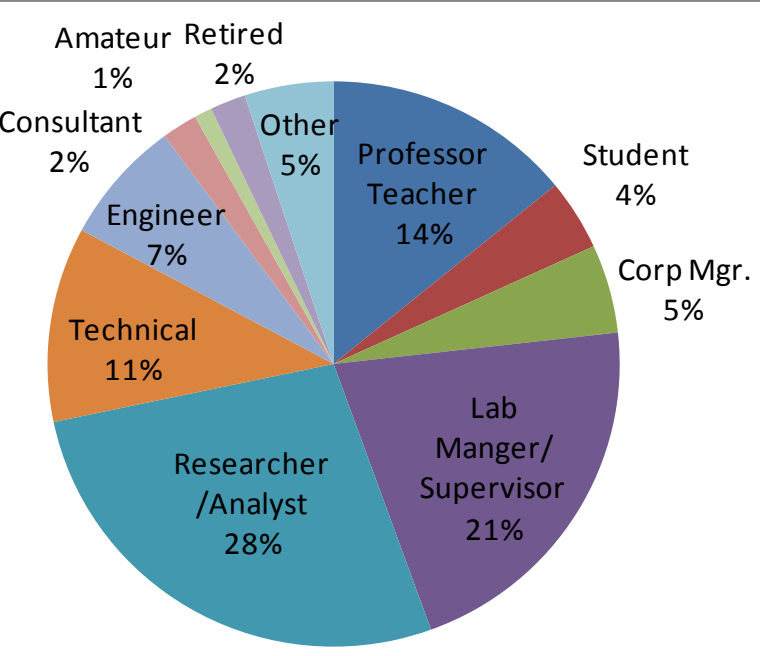

4. Which category best describes your general WORK area?

- Basic/Applied Research

- Production support

- Failure analysis/Quality Control or Assurance

- Clinical

- Teaching

- Independent Testing/Consulting

- Vendor/Supplier

- Service

- Amateur/Hobbyist

- Retired

- Other, please specify

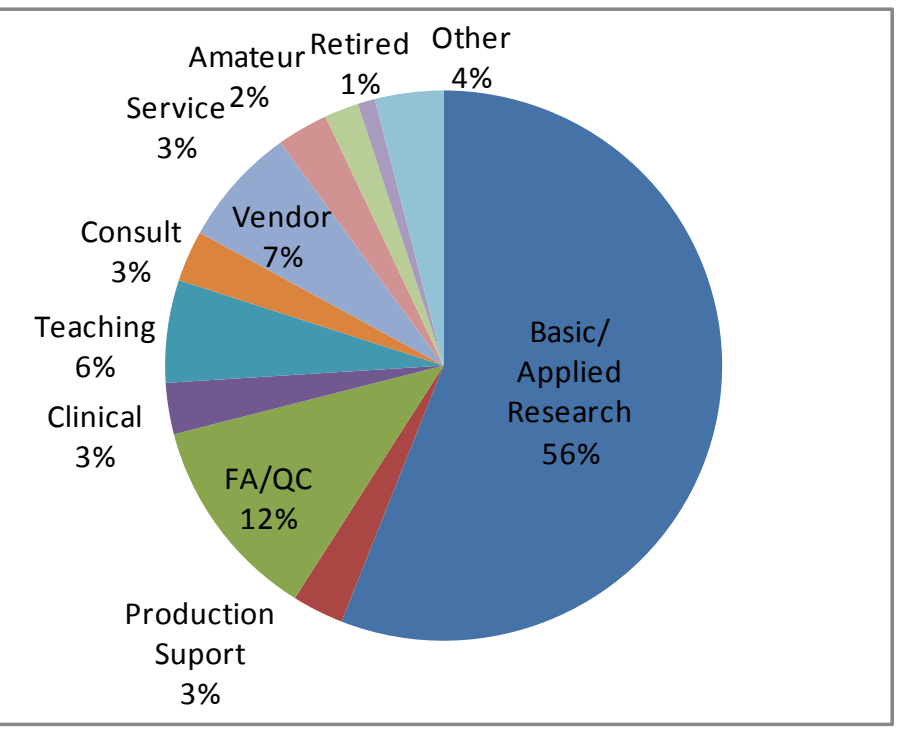

\begin{tabular}{|c|c|c|c|c|c|}
\hline 5. Overall Opinion of Current Microscopy Today Format: \\
\hline & Love it! & Like it & $\begin{array}{c}\text { I'm } \\
\text { Neutral }\end{array}$ & $\begin{array}{c}\text { Some may } \\
\text { like it, but } \\
\text { not me }\end{array}$ & Hate it! \\
\hline $\begin{array}{c}\text { Overall look of } \\
\text { Microscopy Today }\end{array}$ & $16 \%$ & $58 \%$ & $20 \%$ & $5 \%$ & $1 \%$ \\
\hline $\begin{array}{c}\text { Amount of editorial } \\
\text { content }\end{array}$ & $10 \%$ & $52 \%$ & $35 \%$ & $2 \%$ & $0 \%$ \\
\hline $\begin{array}{c}\text { Number of } \\
\text { advertisements }\end{array}$ & $4 \%$ & $40 \%$ & $48 \%$ & $7 \%$ & $1 \%$ \\
\hline $\begin{array}{c}\text { Placement of adver- } \\
\text { tisements (right page } \\
\text { only, opposite article) }\end{array}$ & $13 \%$ & $44 \%$ & $37 \%$ & $5 \%$ & $1 \%$ \\
\hline $\begin{array}{c}\text { Dense/no-white-space } \\
\text { format }\end{array}$ & $17 \%$ & $43 \%$ & $31 \%$ & $8 \%$ & $1 \%$ \\
\hline
\end{tabular}

6. Would you like to see a more open format containing fewer but slightly longer articles?

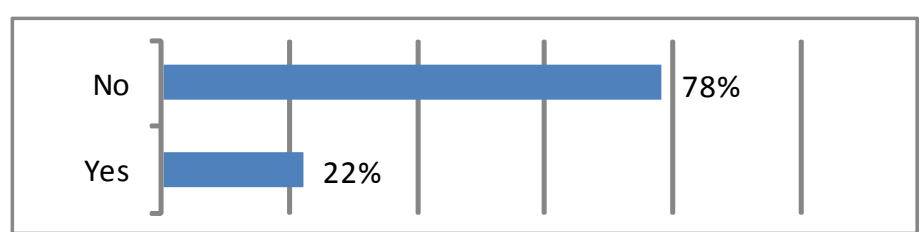

7. Which of the following Microscopy Today sections do you read?

- Carmichael

- Dear Abbe

- Index of Advertisers

- Industry News

- Microscopy 101

- NetNotes

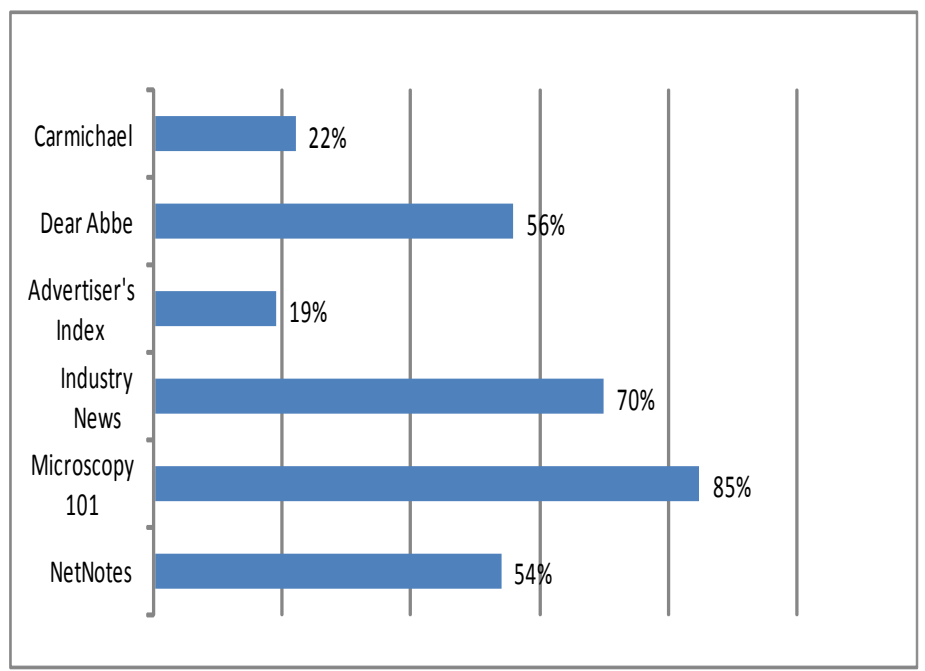

8. How many articles do you typically read per issue?

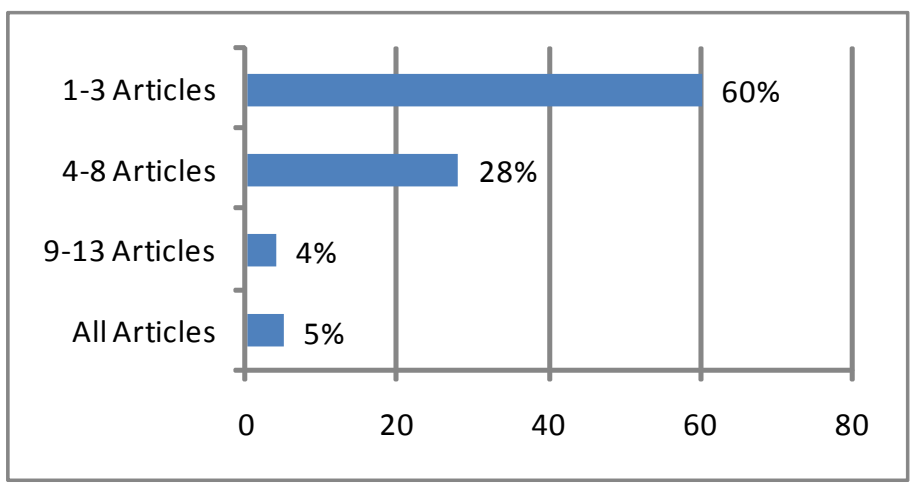




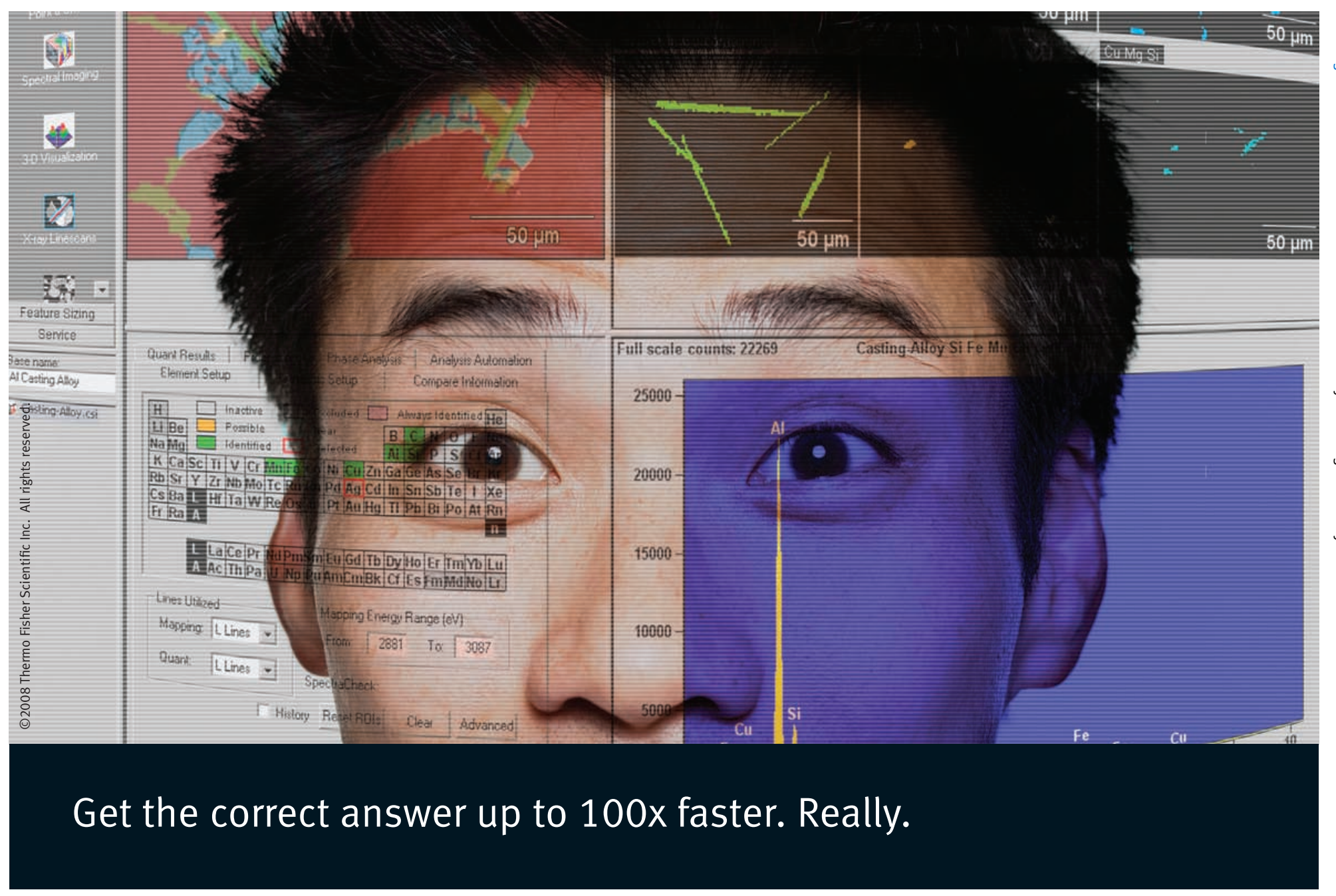

Precision and Speed The Thermo Scientific NORAN System 7 speeds you to answers with blazing fast processing at more than 1,000,000 counts per second. Our impeccable accuracy gives you confidence in your results.

Manual or Automatic? In one system you get the ultimate in automation as well as the flexibility to examine your sample manually. You gain the time saving convenience of automatic quantitative mapping and Point \& Shoot analysis without sacrificing control.

A Pleasure to Use Included with the powerful spectral and imaging hardware is a suite of software unparalleled in the industry. Just one click to create a report or analyze samples outside the lab with network ready data analysis.

Experience the speed of the NORAN System 7. Sample our demo at www.thermo.com/reallyfast.

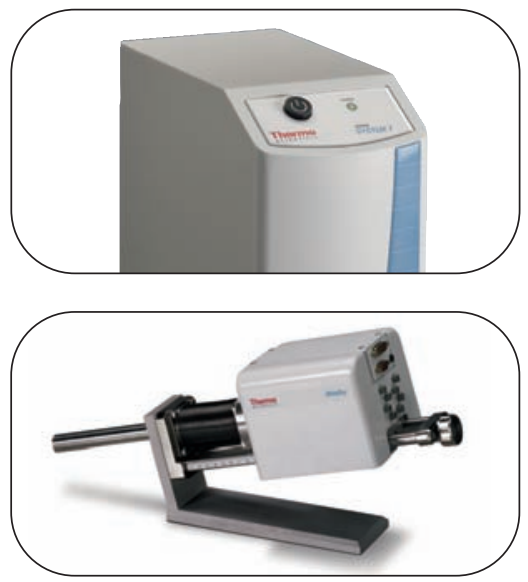

Thermo Scientific NORAN System 7 The optimum combination of detector, analyzer and software for X-ray microanalysis. 
9. How do you use the ads in Microscopy Today?

- Page through, looking at the visual aspects

- Page through to see which companies have ads

- Look up specific advertisers in the Index of Advertisers

- Use the URL in the ad to check out the company website

- Use the phone number in the ad to call about a product

- Look at the specific model/number of equipment shown

- Look specifically for new performance specifications

- Look specifically for ads for new job openings

- Other, please specify

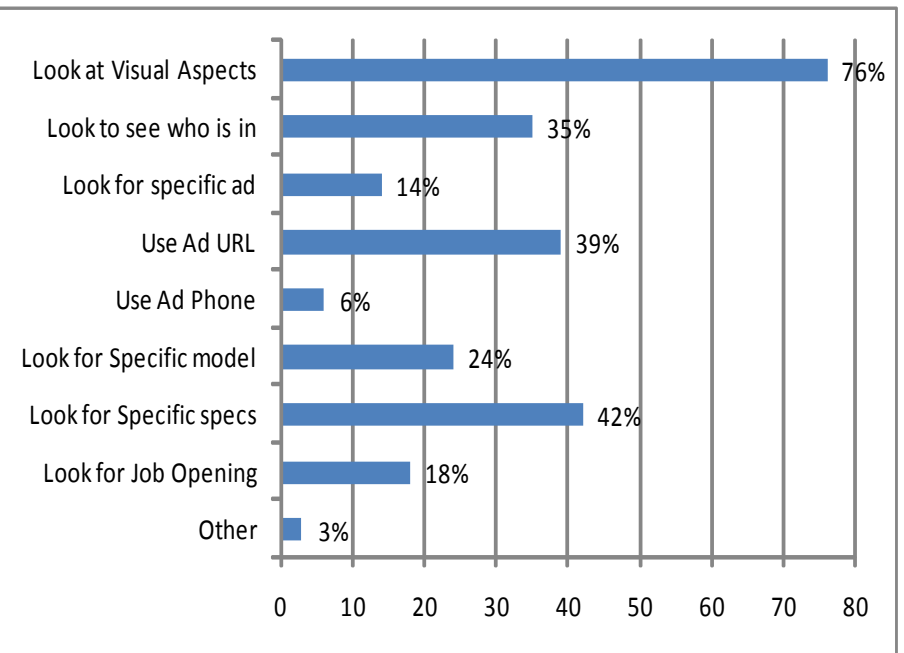

10. What specifically catches your eye in the ads?

- Color

- Size

- Images within the ad

- Technology area

- Applications

- Technical specifications

- Traditional concepts

- "Cute" or different approaches to the market

- Other, please specify

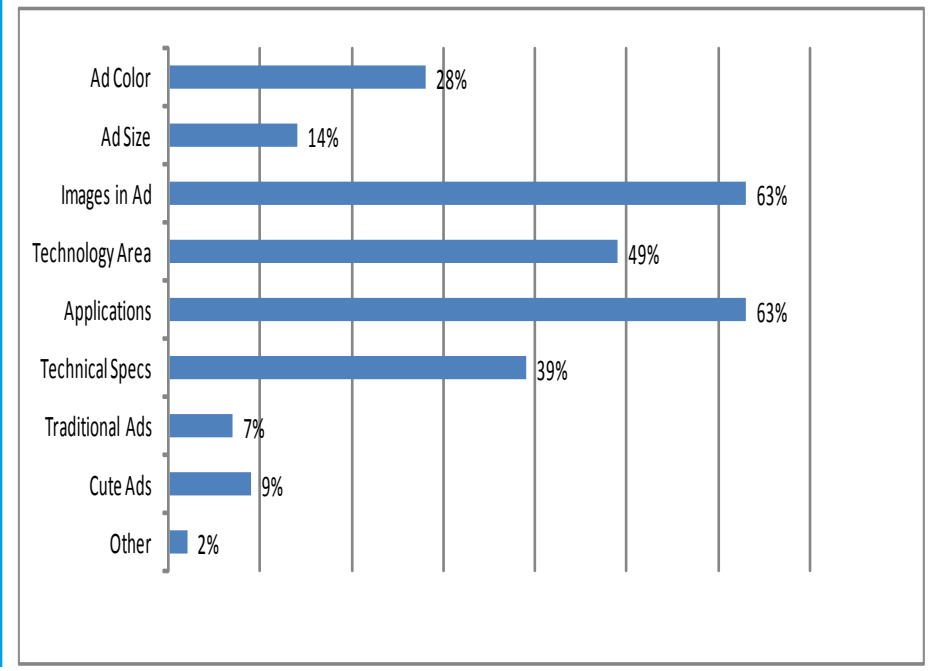

11. Which of the following items has the greatest impact on your buying choices?

- Ads

- Articles with applications

- Articles that are strictly science based

- Technical specifications and parameters

- Other, please specify

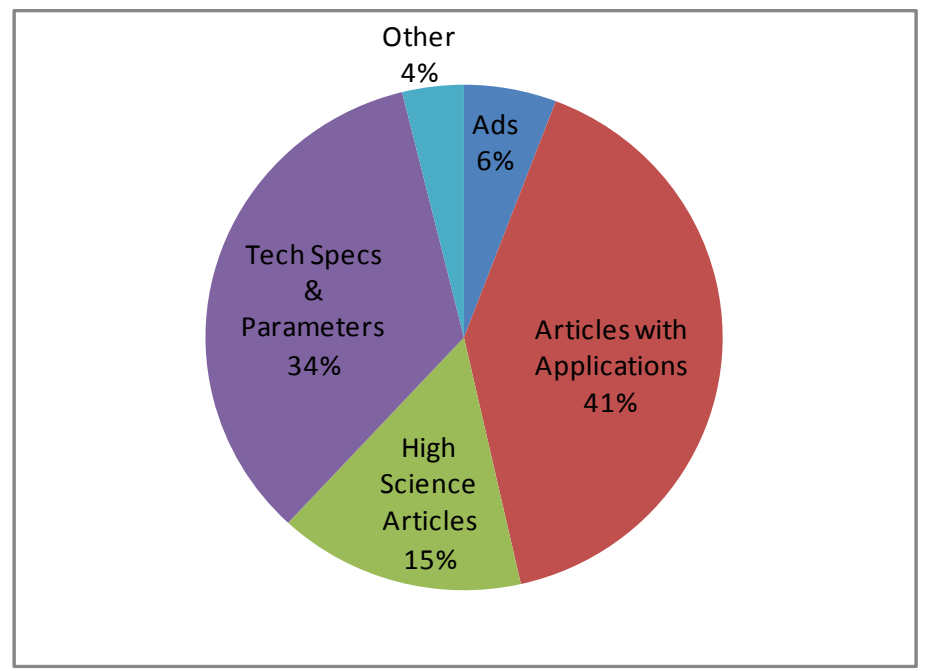

We interpret this to mean that scientists do not write a purchase order based on looking at an ad only. An ad is an entry point to see what is available in the market and to seek more information. Articles with applications, that provide far more information than an advertisement can possibly contain, have an even greater influence on buying decisions. Of course, there is no one item that informs a purchase decision. All of the categories above play a part along with other forms of input.

\section{If there were an electronic version of Microscopy Today as} well as a printed version, to which would you be more likely to subscribe?

- Electronic

- Print

- Both

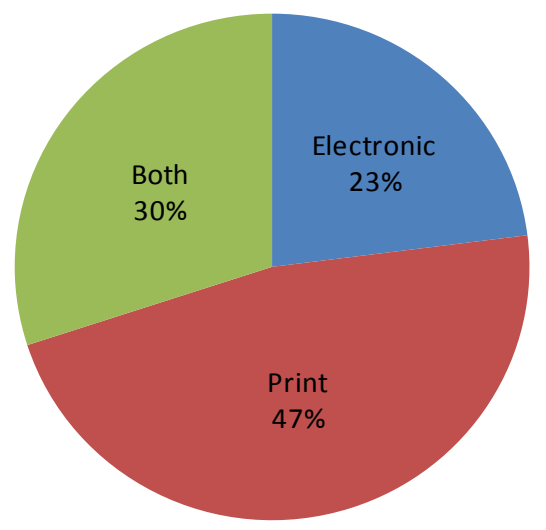




\section{Breadth of Coverage}

The re-styled Microscopy Today will have an editorial board. It will be more pragmatically oriented than the editorial board of the Society's scientific journal, Microscopy \& Microanalysis. We want to make sure that this board reflects your interests. Below is an alphabetical list of categories in which articles have appeared recently in Microscopy Today.

AFM/SPM

Atom Probe Tomography

Applications/Industrial

Applications/Biological

Confocal/Fluorescence

Polarized Light

Clinical/Pharmaceutical

Electron microscopy

EDS, WDX, EELs, etc.

Food Science

Forensic

Geology, Environmental, \& Earth Sciences

Lab Management and Control

Materials (Metals, Polymers, Nanotech, Semiconductors, etc.)

Microscopy Education K-30

Sample Prep (Biological/Clinical, Materials, Nanotech., Semiconductors)

New Technologies/Vendors (Scopes, software, accessories, etc).
13. The following new categories have been recommended.

Which would be of interest to you?

- Microscopy/Spectroscopy hybrid technologies (Raman, NIR, FT-IR, etc.) This item received a yes vote from $71 \%$ of the respondents.

- Physical testing (micro/nano indentation, elasticity, thermal properties, etc.) This item received a yes vote from $47 \%$ of the respondents.

- Other technologies you would like see? $21 \%$ of the respondents made 141 suggestions of topic areas. Again, please contact one of the authors to get a list of all "Other" responses."

\section{Discussion}

These survey results indicate that Microscopy Today is wellreceived by its readership. The current page format is preferred by most readers. Most people typically split their time between looking at articles and looking at advertisements. Interestingly, the sections viewed most are Microscopy 101 and Industry News. Advertisements with interesting images appear to be most popular with readers. Articles describing applications for microscopy/microanalysis instrumentation appear to have the greatest impact on buying choices. Interest in light microscopy combined with Raman and FTIR shows that this is an area where expanded coverage is warranted.

\section{STOP HASSLING WITH \\ MULTIPLE SERVICE CONTRACTSL}

START by putting all of our instruments under one service contract with MAS (regardless of make or model). Our expert EM SERVICE GROUP has the knowledge and skills to keep your instrument working at its best.

\section{TEM'S / SEM'S PREP EQUIPMENT SPECIAL SERVICES}

HITACHI TOPCON

JOEL

ISI

AMRAY CAMBRIDGE
VACUUM COATERS

PLASMA ASHERS

SPUTTER COATERS

ION MILLS
STAGES

BEAM BLANKERS

CUSTOM DEVICES

\section{NEW NEW NEW}

Authorized service representatives

for Gatan preparation equipment and Topcom TEM'S.
Contracts and On-Demand

Emergency Service at

Reasonable Rates from

Factory Trained Specialist

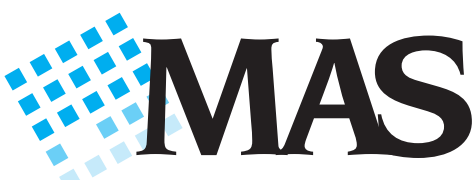

800-421-8451

3945 Lakefield Court Suwanee, Georgia 30024 770-866-3200 FAX 770-866-3259 ADVANGED ANALYTIGAL PRODUGTS AND SERVIGES 